\title{
FutureJournal
}

\section{O Papel da Gestão Documental nos Processos de Gestão do Conhecimento}

Márcio Aparecido Nogueira Viana

Especialista em Gestão da Informação Digital pela Fundação Escola de Sociologia e Política de São Paulo (FESPSP), Brasil maviana@vunesp.com.br

Valéria Martin Valls

Docente de Pós-Graduação da Fundação Escola de Sociologia e Política de São Paulo (FESPSP), Brasil

valls@uol.com.br

\section{RESUMO}

A identificação da interface entre as atividades de gestão de documentos, da informação e do conhecimento, com o intuito de demonstrar o papel dos arquivos como auxiliares nos processos de criação e compartilhamento do conhecimento corporativo foram os elementos centrais desta pesquisa. Por meio de pesquisa bibliográfica, foi contextualizado o trabalho, onde primeiramente foram definidos os temas que permeiam as teorias que compõem a Gestão da Informação e do Conhecimento, seguido pelo estudo das práticas arquivísticas e da Gestão Documental. A partir desta fundamentação teórica, foram definidas similaridades entre as disciplinas e a forma como os arquivos podem contribuir na gestão do conhecimento e suas práticas. Deste modo, o resultado esperado com esta pesquisa é a produção de uma análise que identifique a área de arquivos e seus profissionais como parte importante nos processos de gestão do conhecimento, levando a organização a ser mais eficiente nas tomadas de decisões que garantem 0 desenvolvimento sustentável de suas operações.

PALAVRAS-CHAVE: Gestão do conhecimento. Gestão da informação. Gestão documental. Arquivos, documentos. 


\section{The Role of Document Management in Knowledge Management Processes}

\section{ABSTRACT}

Identifying the interface between activities of document management, information management and knowledge management, in order to demonstrate the role of archives as aids in the process of creation and sharing of corporate knowledge were the central elements of this research. The work was contextualized through bibliographical research, where we first defined the themes that permeate the theories that comprise information management and knowledge management, followed by the study of archiving and document management practices. From this theoretical framework, were defined similarities between disciplines and the way the archives can contribute to knowledge management and its practices. Thus, the expected outcome of this research is to produce an analysis that identifies the filing process and its professionals as an important part in the processes of knowledge management, helping the organization to be more efficient in making decisions that ensure sustainable development of its operations.

KEY-WORDS: Knowledge management. Information management. Document management. Archives documents. 


\section{INTRODUÇÃO}

Em um ambiente extremamente competitivo, é primordial para as empresas que as informações produzidas, recebidas e acumuladas no exercício de suas atividades sejam registradas. Essas informações, ainda que muitas vezes sejam encaradas apenas como fonte para apoio a demandas jurídicas e administrativas, podem e devem servir como instrumento para a implantação de ações de gestão do conhecimento.

O conhecimento, como será abordado nesta pesquisa, atualmente é fator importante na tomada de decisões, especialmente em um contexto socioeconômico em que a globalização e a velocidade da informação pautam o mercado. Nesse sentido, uma das formas de abordar o conhecimento para apoio em ações é recorrer à memória corporativa, em especial à que está registrada em documentos gerenciados pelos profissionais da informação, no caso deste trabalho em específico, os profissionais que lidam com a gestão documental.

Segundo Longo et al. (2014, p. 163), com a quantidade sempre crescente de acontecimentos, surgiu a necessidade de criar suportes para registrá-los e de pessoas para cuidar desses suportes informacionais, hoje armazenados em centros de documentação, entre outros. Esses centros, por meio da atividade de seus profissionais, atuam amparados por uma série de procedimentos, estabelecidos por leis e normas técnicas, que garantem a efetiva preservação da memória relevante para dar suporte às atividades das organizações.

A intenção desta pesquisa é demonstrar o papel da gestão documental nos processos de gestão do conhecimento, identificando e descrevendo os conceitos pertinentes às áreas em questão, além de traçar um panorama sobre a gestão da informação, contextualizando-o por meio de pesquisa bibliográfica, a fim de elucidar as principais atividades dos profissionais de arquivos, e como estas se relacionam com as práticas de gestão do conhecimento, comparando-as e demonstrando os pontos de convergência entre as áreas. Na metodologia, apresenta-se a sequência dos temas abordados na pesquisa, detalhando a linha do tempo adotada para a construção das conexões entre as áreas. Sendo assim, procurou-se analisar 
as similaridades presentes nas atividades de gestão documental com as práticas de gestão da informação e do conhecimento, a fim de estabelecer as interfaces necessárias para que os profissionais da informação possam estar inseridos nos processos de gestão do conhecimento, de modo que auxiliem na criação e no uso do conhecimento corporativo, levando à inovação constante e garantindo a sustentabilidade econômica da empresa.

\section{METODOLOGIA}

Para fundamentação desta pesquisa, foram realizadas as seguintes atividades: pesquisa bibliográfica e revisão de literatura, além de reuniões para definição dos objetivos da pesquisa.

A partir do levantamento bibliográfico e da revisão da literatura, foram construídas as bases para o estudo comparativo dos modelos de gestão abordados, apoiado pela adaptação e criação de quadros comparativos entre as práticas e modelos de gestão e suas similaridades. Para esta pesquisa, foram consultadas publicações dos principais autores relacionados à gestão do conhecimento, como Nonaka e Takeuchi, Choon Wei Choo, Peter Senge, Davenport e Prusak, além de nomes ligados à filosofia e à aprendizagem, como Marilena Chauí, Edgar Morin e Jayme Teixeira Filho, no que diz respeito à definição de conhecimento. Além deles, foram consultadas publicações voltadas à gestão da informação e do conhecimento, de autores como Leonardo Souto, Marta Valentim, Rose Mary Juliano Longo, entre outros. Por fim, foi utilizada a bibliografia referente à gestão documental e à arquivística, representada por alguns de seus principais nomes, como Heloisa Liberalli Bellotto e Marilena Leite Paes, além de autores de livros recentes da área, com temas que avançam para o relacionamento entre a arquivologia e outras práticas, como no caso dos autores Vanderlei Batista dos Santos e Charlley Luz.

Inicialmente, a revisão de literatura se dá com um breve panorama sobre gestão da informação e gestão do conhecimento, passando pelos principais temas e teóricos das áreas, apontando por meio de quadro comparativo as diferenças entre dado, informação e conhecimento, e trazendo a definição de cada um desses temas. Em seguida, é descrito o 
processo de criação do conhecimento, como a aprendizagem é importante no ambiente corporativo e as diferenças entre conhecimento tácito e explícito, explicando-se a espiral do conhecimento e a teoria das cinco disciplinas, com base na literatura, em especial na publicação de Peter Senge. Passa-se, então, para a definição da gestão do conhecimento, como modelo de gestão responsável por coletar e difundir o conhecimento organizacional, apresentando suas características principais. Também é feita uma explanação sobre a gestão documental, suas práticas e normas e sua importância. Por fim, por meio de quadros comparativos e análise de itens, são observadas as interfaces entre as gestões documental, da informação e do conhecimento, a fim de alcançar os objetivos deste trabalho, apontando a possibilidade de uso da gestão documental como auxiliar nos processos de gestão da informação e do conhecimento.

\section{REVISÃO DE LITERATURA}

\subsection{BREVE PANORAMA SOBRE INFORMAÇÃO E CONHECIMENTO}

De acordo com Davenport e Prusak (1998, p. 18), os conceitos sobre dado, informação e conhecimento podem ser representados conforme o Quadro 1, a seguir.

\begin{tabular}{|c|c|c|}
\hline Dado & Informação & Conhecimento \\
\hline $\begin{array}{l}\text { Simples observação sobre } \\
\text { estado do mundo; } \\
\text { Facilmente estruturado; } \\
\text { Facilmente obtido por } \\
\text { máquinas; } \\
\text { Frequentemente } \\
\text { quantificado; } \\
\text { Facilmente transferível. }\end{array}$ & $\begin{array}{l}\text { Dados dotados de relevância } \\
\text { e propósito; } \\
\text { Requer unidade de análise; } \\
\text { Exige consenso em relação } \\
\text { ao significado; } \\
\text { Exige necessariamente a } \\
\text { mediação humana. }\end{array}$ & $\begin{array}{l}\text { Informação valiosa da } \\
\text { mente humana; } \\
\text { Inclui reflexão, síntese, } \\
\text { contexto; } \\
\text { De difícil estruturação; } \\
\text { De difícil captura em } \\
\text { máquinas; } \\
\text { Frequentemente tácito; } \\
\text { De difícil transferência. }\end{array}$ \\
\hline
\end{tabular}

\section{Quadro 1: Dado, informação e conhecimento}

Ou seja, para que um dado seja considerado informação, é necessário um trabalho de análise e tratamento, para obter consenso 
quanto aos termos que formam seu significado e sua relevância, de modo que esteja alinhado com os anseios de seu público-alvo, a ponto de ser um possível gerador de conhecimento. Uma vez definida a perspectiva em que a informação será trabalhada, será possível pensar-se em estratégias para alavancar a criação do conhecimento organizacional.

Choo (2006, p. 403) indica que muitas das informações que têm impacto sobre a organização são insinuações sutis, mais um potencial do que uma prescrição para a ação. Segundo ele, é preciso que a informação seja transformada em conhecimento para que possa guiar a ação. Para tal, é necessária uma estrutura unificadora, com recursos técnicos e tecnológicos e políticas de uso e acesso que possam garantir o correto fluxo dessa transformação.

Davenport e Prusak (1998, p. 6) definem que "o conhecimento é uma mistura fluida de experiência condensada, valores, informação contextual e insight experimentado, a qual proporciona uma estrutura para avaliação e incorporação de novas experiências e informações". Segundo os autores, nas organizações, o conhecimento costuma estar embutido não só em documentos e repositórios, mas em rotinas, processos, práticas e normas organizacionais. Ou seja, em termos gerais, o conhecimento é formado pelas informações absorvidas, aliadas às nossas vivências e ao convívio social. Chauí (2000) afirma que conhecer é alcançar o idêntico, o imutável. De acordo com ela, através dos sentidos se tem acesso a um mundo em constante mudança. Em sua obra Convite à filosofia, Marilena Chauí demonstra como o conhecimento sempre foi discutido pelos grandes filósofos. Podem-se destacar, entre eles, as teorias de Platão e Aristóteles. Segundo a autora, Platão distingue quatro formas ou graus de conhecimento: crença, opinião, raciocínio e intuição intelectual; enquanto Aristóteles divide as formas de conhecimento em: sensação, percepção, imaginação, memória, raciocínio e intuição. Platão pregava a separação do conhecimento sensível (crença e opinião) do conhecimento intelectual (raciocínio e intuição), afirmando que somente o segundo corresponde à verdade. Já para Aristóteles, o conhecimento vai sendo formado e enriquecido por acumulação das informações trazidas por todos os graus, que se completam em uma relação de continuidade. Segundo Morin (2000), 
o conhecimento é sempre uma tradução, seguida de uma reconstrução, ou seja, cada indivíduo recebe de outro uma informação que, através de suas experiências, decodifica, criando significado para desenvolver seu conhecimento próprio. Ainda segundo Morin (2000), não há diferença intrínseca entre uma percepção e uma alucinação, de modo que se faz uso do conhecimento prévio para reforçar ou desfazer uma impressão sobre o que se observa. Isso reforça a ideia de como as organizações devem considerar o conhecimento prévio do indivíduo no processo de aprendizagem e saber trabalhá-lo estrategicamente, a fim de criar significado. A criação de significados está intimamente ligada à memória do ser humano. Tal memória é que difere um ser humano do outro, pois cada um vivencia experiências diferentes no decorrer da vida.

O francês Bergston (citado por Chauí, 2000, p. 163) define seis tipos de memórias, uma das quais é chamada de memória social ou histórica, pois "(...) é fixada por uma sociedade através de mitos de fundadores e de relatos, registros, documentos, fatos e lugares que possuem significado para a vida coletiva". O conceito de acúmulo de conhecimento de Aristóteles, atrelado ao tipo de memória social ou histórica de Bergston, enriquece o conceito central da teoria de Ausubel (citado por Moreira, 2010) sobre o processo de Aprendizagem Significativa. Nesse processo, uma nova informação (representada por $a^{\prime}$ ) relaciona-se a um aspecto relevante da estrutura de conhecimento prévio do indivíduo (representado por $A^{\prime}$ ) e transforma-se na Aprendizagem Significativa: A'a'. De acordo com Feuerstein (citado por Turra, 2007), o processo de aprendizagem pode ser melhorado por meio de um mediador, ou seja, uma pessoa que trabalha interagindo com o aprendiz, estimulando suas funções cognitivas, organizando o pensamento e melhorando processos de aprendizagem. Esse mediador, quando dotado de intenção, poderá gerar e transferir informações suficientes para que o aprendiz gere significado e construa conhecimento.

A aprendizagem mediada é o caminho pelo qual os estímulos são transformados pelo mediador, guiado por suas intuições, emoções e sua cultura. O mediador avalia as estratégias, seleciona as que são mais apropriadas a determinada situação, amplia algumas, ignora outras, faz esquemas. É por meio desse processo de mediação que a estrutura cognitiva da criança adquire padrões de comportamento que determinarão sua capacidade de ser modificada. Assim, quanto menos mediação for 
oferecida, menor será a possibilidade de o mediado desenvolver a capacidade de se modificar. (Turra, 2007, p. 303)

Certamente, uma organização na qual os colaboradores sejam orientados a exercer o papel de mediadores, considerando as premissas acima citadas, será uma organização do conhecimento.

Teixeira Filho (2010) ressalta que, na visão construtivista, se está sempre repensando os métodos de investigação, sempre buscando as possíveis incoerências naquilo que se julga saber. Em seu artigo "Estratégias para o caos: sobre a transposição de teorias da física e da matemática para a administração", o autor explana sobre as formas de abordar o desconhecido. Neste caso, cabe uma analogia (o que em si já é uma forma de abordagem): nas estratégias de propaganda nazista, idealizadas por Joseph Goebbels, era forte a ideia de que é mais fácil distorcer o que não se conhece. É dele a célebre frase que dá conta de que "uma mentira repetida várias vezes vira verdade". Lastres e Ferraz (1999) elencam fatores que atuam sobre mudanças, indicando que o "novo" sempre causa certa resistência e dúvida, porém é um agente de expansão do conhecimento, desde que haja estratégias de controle:

\begin{abstract}
Mudanças implicam resistência: os agentes econômicos estabelecidos e suas verdades tentarão sempre postergar a introdução do "novo", ameaça talvez à sua própria existência. Mudanças induzem insegurança: o "novo" e seus códigos de funcionamento ainda são desconhecidos, implicam aprendizado, erros, acertos. Mas mudanças também implicam expansão dos limites de conhecimento existentes: para que o "novo" ocupe seus espaços é necessário dominar uma heurística diferente, um método distinto de resolver e controlar problemas. Para melhorar esse processo de aprendizagem significativa ( $\left.A^{\prime} a^{\prime}\right)$ dentro das organizações, é necessário que haja uma preocupação no que se diz respeito à forma de transferência de informação e que essa esteja alinhada ao conhecimento prévio dos colaboradores, para que o processo seja eficiente e eficaz. (Lastres \& Ferraz, 1999, pp. 27-28)
\end{abstract}

No desempenho de suas funções, seja em suas atividades-meio ou fim, uma organização gera e consome informação, originada tanto interna quanto externamente. Essa informação pode ser registrada em diversos suportes, dando origem aos arquivos institucionais, que servem de apoio para a tomada de decisões acerca de suas atividades. Num ambiente de negócios, a eficiência na gestão da informação é de suma importância, uma vez que, a cada dia, a maior preocupação no mundo corporativo é com o 
excesso de dados não estruturados em um contexto capaz de auxiliar na criação de conhecimento.

A informação sintoniza o mundo. Como onda ou partícula, participa na evolução e na revolução do homem em direção à sua história. Como elemento organizador, a informação referencia o homem a seu destino, mesmo antes de seu nascimento, por meio de sua identidade genética e, durante sua existência, por meio de sua competência em elaborar a informação para estabelecer sua odisseia individual no espaço e no tempo. (Barreto, 2012, p. 3)

Assim, quando se diz que uma empresa ou instituição é uma organização do conhecimento, depreende-se que esta tem a capacidade de promover, por meio de interações, a criação do conhecimento, conforme se explica a seguir.

\subsection{A CRIAÇÃO DO CONHECIMENTO}

Segundo Takeuchi e Nonaka (2008), o modelo de criação do conhecimento parte do pressuposto de que o conhecimento humano é criado e expandido por meio da interação social, sendo a interação denominada conversão do conhecimento. Enquanto o conhecimento tácito é subjetivo e difícil de ser capturado, o conhecimento explícito é registrado em documentos e é facilmente comunicável. A criação do conhecimento surge a partir da interação entre o conhecimento tácito e o explícito. Os autores definem o processo dinâmico de criação do conhecimento como espiral do conhecimento: "A criação do conhecimento organizacional é um processo em espiral, que começa no nível do indivíduo e vai subindo, ampliando as comunidades de interação que cruzam fronteiras entre seções, departamentos, divisões e organizações" (Takeuchi \& Nonaka, 2008). A criação do conhecimento empresarial depende do envolvimento pessoal, e em vários processos de conversão do conhecimento tácito e explícito e inclui todo o grupo, o indivíduo, a organização e o ambiente. 


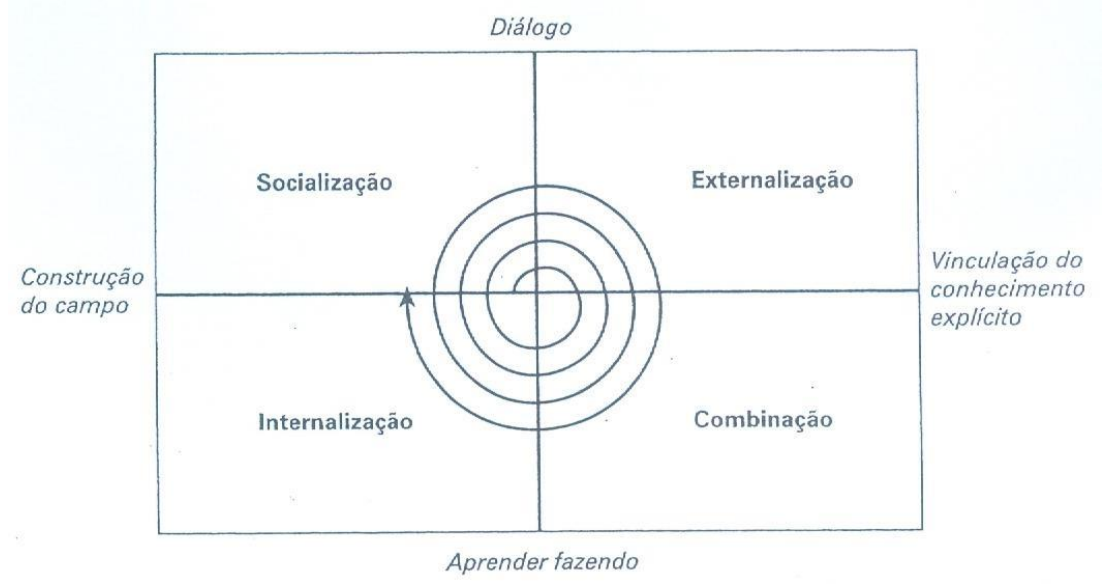

Figura 1: Espiral do conhecimento

Fonte: Takeuchi e Nonaka (2008, p. 69)

Nessa espiral, os conhecimentos tácito e explícito complementam-se e transformam-se, conforme descrito a seguir:

- de tácito para tácito: dá-se por meio da socialização, que está relacionada à convivência e à interação entre as pessoas, mesmo sem haver comunicação verbal;

- de tácito para explícito: dá-se pela externalização, ou seja, o transmissor exprime uma representação do seu conhecimento tácito em uma linguagem escrita ou verbal, de modo que seja explicitado ao receptor;

- de explícito para explícito: dá-se pela combinação, quando os conhecimentos explícitos são combinados, gerando novos conhecimentos. Pode ser exemplificado no caso de uma coleta de informações de diversos setores, que juntos propiciem a geração de relatórios baseados nessas informações;

- de explícito para tácito: dá-se pela internalização, processo criado a partir da interpretação de conhecimentos explícitos, presentes em manuais, normas, instruções e conteúdos que são absorvidos pelo receptor, podendo transformar-se em conhecimento tácito.

De acordo com Nonaka e Takeuchi, a principal razão do sucesso das empresas japonesas é sua competência na construção do conhecimento organizacional. A construção do conhecimento é conseguida quando se reconhece o relacionamento sinérgico entre o conhecimento tácito e o conhecimento explícito dentro de uma organização, e quando são elaborados processos sociais capazes de criar novos conhecimentos por meio da conversão do 
conhecimento tácito em conhecimento explícito. (Choo, 2006, pp. 36-37)

Nesse modelo oriental, é forte a ideia de que os processos de criação do conhecimento são os insumos para a inovação. Essa ideia também é clara para Lemos (1999, p. 127), que indica que "o processo de inovação é, portanto, um processo interativo, realizado com a contribuição de variados agentes de uma mesma empresa, entre empresas distintas e com outras organizações, como aquelas de ensino e pesquisa". Essa fala vai ao encontro das ideias que dão conta da necessidade empresarial de criar laços e redes de relações para formar as organizações de aprendizagem, conceito que está ligado diretamente aos ideais de Peter Senge, desenvolvedor da teoria das cinco disciplinas. Senge defende a ideia de que, através da formação da organização que aprende, as pessoas criam condições de inovação, por meio do aprendizado contínuo.

O autor argumenta que a forma como as organizações são projetadas e gerenciadas tem sérias implicações nas suas capacidades de aprendizagem.

Quando alguém pergunta a uma pessoa o que ela faz para viver, a maioria descreve tarefas que executa no dia a dia, e não o propósito maior da empresa onde trabalha. A maioria se vê sobre um sistema que tem pouca ou nenhuma influência. Eles "fazem seu trabalho", dedicam seu tempo e tentam conviver com forças sobre as quais não exercem controle algum. (Senge, 2011, p. 52).

Senge conclui que, quando as pessoas na organização focam somente o cargo que ocupam, desenvolvem pouco senso de responsabilidade em relação aos resultados da organização como um todo. Mas o que fazer diante de um cenário em que os resultados das ações não são perceptíveis no longo prazo? De acordo com o autor, o aprendizado mais poderoso vem da experiência direta, através de um processo direto de tentativa e erro. Dentro das organizações, criou-se uma ilusão de que o aprendizado ocorre através da experiência. Porém, atitudes geram resultados que vão além do horizonte de aprendizado, tornando impossível aprender através da experiência direta dentro do ambiente organizacional.

Aí está o dilema essencial da aprendizagem que as organizações têm de enfrentar: aprendermos melhor com a experiência, todavia nunca experimentamos diretamente as consequências das nossas decisões mais importantes. (Senge, 2011, p. 57) 
Senge também define alguns comportamentos inibidores da aprendizagem que nos remetem ao processo educacional das escolas, que, a exemplo das organizações, só recompensa as pessoas competentes em defender seus pontos de vista, em "arranhar o verniz", mas não em indagar sobre os problemas complexos e importantes da organização.

O autor descreve as cinco disciplinas que estão gradualmente convergindo para inovar as organizações e transformá-las em organizações que aprendem:

- domínio pessoal: são as competências e mobilidades do indivíduo e sua disposição de colocar o conhecimento a serviço da organização. Senge defende que nada acontece até que exista visão com um propósito subjacente. Por outro lado, o propósito sem visão não faz sentido em termos de escala. Domínio pessoal é um processo pelo qual se enfoca e reenfoca continuamente o que realmente se deseja, a verdadeira visão. Senge posiciona a tensão criativa no centro da disciplina de domínio pessoal e define-a com a fonte de energia representada pelo hiato entre a visão e a realidade atual. As estruturas que caracterizam o domínio pessoal como disciplina são a tensão criativa, a tensão estrutural e o conflito pessoal. O autor lembra ainda que a tensão criativa frequentemente está associada a uma tensão emocional que pode levar à "mediocridade" se não for bem gerenciada. O autor argumenta que se tem pelo menos uma entre duas crenças contraditórias ao domínio pessoal, sendo a mais comum a crença na impotência ou na incapacidade de realização. Outra crença diz respeito à sensação de demérito, a de não merecimento. Senge define a organização comprometida com o domínio pessoal como um espaço onde exista compromisso com a verdade e onde seja seguro para as pessoas criarem suas visões e questionarem as visões alheias;

- modelos mentais: de acordo com o autor, os modelos mentais são "(...) pressupostos profundamente arraigados, generalizações, ilustrações, imagens ou histórias que influem na nossa maneira de compreender o mundo e nele agir". Ou seja, os modelos mentais de cada indivíduo definem como ele irá perceber o que está acontecendo à sua volta, como irá se sentir com isso, como pensa e como irá agir. Muitos movimentos estratégicos e administrativos dentro das empresas não podem 
ser colocados em prática por causa de modelos mentais tácitos muito poderosos. Segundo Senge, esses modelos mentais definem a forma de agir e a visão de mundo, ou seja, a forma como o indivíduo interpreta o universo a seu redor e interage com ele. A forma como os modelos mentais moldam as percepções de mundo também tem implicações no mundo dos negócios. Modelos mentais podem impedir a aprendizagem e comprometer a competitividade das organizações. Senge cita o case de três montadoras de automóveis norte-americanas que durante décadas se apoiaram em crenças de que a proposição de valor do negócio estava baseada no modelo dos automóveis e não em sua qualidade ou confiabilidade até que as montadoras japonesas e alemãs reeducaram os consumidores e abocanharam 38\% do mercado. Senge desafia os gerentes a entenderem suas visões de mundo como premissas e não como fatos.

Se não tiverem habilidades em indagar sobre suas próprias formas de pensamento e a das outras pessoas, ficarão limitados na experimentação coletiva de novas formas de pensamento. Além disso, se não houver uma filosofia e uma compreensão dos modelos mentais estabelecidas na organização, as pessoas perceberão equivocadamente o propósito do pensamento sistêmico como traçar diagramas para desenvolver "modelos" elaborados do mundo, e não de aperfeiçoar os nossos modelos mentais. (Senge, 2011, p. 227)

- visão compartilhada: a empresa deve ter uma missão forte, totalmente alinhada a suas estratégias e adotar uma visão compartilhada, para que todos possam enxergar onde a empresa está e aonde ela quer chegar;

- aprendizagem em equipe: como citado anteriormente, o aprendizado coletivo tem mais valor para a organização do que o aprendizado do indivíduo, isso porque, quando existe uma unidade de aprendizagem focada no grupo, esses integrantes tendem a crescer mais rápido e, consequentemente, a organização cresce também. Segundo Senge, a disciplina da aprendizagem em equipe é o processo de alinhamento e desenvolvimento da capacidade da equipe de criar os resultados que seus membros realmente desejam. Segundo ele, nunca houve uma necessidade tão grande de dominar a aprendizagem em equipe nas organizações quanto hoje. Senge destaca em sua obra as metáforas das equipes de esportes e das grandes bandas de jazz para ilustrar a ação espontânea e coordenada de seus componentes, característica da 
aprendizagem em equipe. Atualmente a disciplina da aprendizagem em equipe vem adotando as práticas de sessões de diálogo para o desenvolvimento de habilidades da equipe. Senge cita o trabalho de David Bohm sobre a teoria e a prática do diálogo, segundo o qual o instrumento de observação e o objeto observado participam um do outro de forma irredutível, sendo assim, percepção e ação não podem ser separadas. 0 trabalho de Bohm em prol do diálogo é associado a uma perspectiva sistêmica. Tanto a perspectiva quanto as ferramentas do pensamento sistêmico são elementos centrais da aprendizagem em equipe;

- $\quad$ pensamento sistêmico: essa é a quinta disciplina, a qual integra todas demais. O pensamento sistêmico ajuda a enxergar a parte como um todo, e não como peça isolada. Segundo Senge, a quinta disciplina é a base da organização de aprendizagem, já que é ideal que as cinco disciplinas atuem em conjunto.

As nuvens ficam pesadas, o céu escurece, as folhas giram no chão: sabemos que vai chover. Sabemos também que, depois da tempestade, a água da chuva alimentará os lençóis d'água, a quilômetros de distância, e que pela manhã o céu estará claro outra vez. Todos esses eventos estão distantes no tempo e no espaço, mas estão conectados em um mesmo padrão. Um tem influência sobre o outro, uma influência que, em geral, não é aparente. Só poderemos entender o sistema de uma tempestade contemplando o todo, não uma parte individual do padrão. (Senge, 2011, p. 40)

De acordo com Takeuchi e Nonaka (2008, p. 99), o conhecimento necessita de um contexto físico para que seja criado, pois depende de determinado tempo e espaço. Baseados no conceito proposto pelo filósofo japonês Kitaro Nishida, os autores introduzem o que chamam de ba, o qual definem como "um contexto compartilhado em movimento, no qual o conhecimento é partilhado, criado e utilizado". Por outro lado, os autores procuram demonstrar que o ba deve ser entendido não apenas como um espaço físico, como, por exemplo, uma sala de reuniões, mas sim como as interações que se desencadeiam em um tempo e espaço específicos.

O ba é uma forma de organizar a criação de significados, não um modo de organização como a hierarquia ou a rede. Uma empresa pode ser vista como uma configuração orgânica de vários $b a$, onde as pessoas interagem umas com as outras e com o ambiente, com base no conhecimento que possuem e no significado que criam. Quando as empresas são vistas como configurações orgânicas de ba, e não como estruturas organizacionais, é possível ver qual o tipo de conhecimento que deve e pode ser criado, quem 
são as "pessoas certas" com conhecimento inserido, e que tipo de interações são necessárias entre elas para criar conhecimento, sem estar restrito à estrutura organizacional existente. (Takeuchi \& Nonaka, 2008, p. 100)

Dessa forma, pode-se dizer que a organização de informações e documentos está diretamente ligada aos processos e práticas que constituem a gestão do conhecimento, conforme será explicado no capítulo a seguir, uma vez que fazem parte da estrutura da organização, fornecendo dados relevantes para auxiliar na execução de projetos.

\subsection{GESTÃO DO CONHECIMENTO}

Segundo Valentim (2008), a base para implantar um modelo de gestão do conhecimento em uma organização é conhecer e saber utilizar de forma adequada o capital intelectual disponível, motivar constantemente as pessoas quanto à troca de informação e conhecimento.

Implantar a gestão do conhecimento em uma empresa pode contribuir enormemente para que ela permaneça no mercado durante muitos anos, pois saberá dar valor às informações que possui e às pessoas que trabalham na organização, facilitando a geração de novos conhecimentos a partir do relacionamento entre seus colaboradores. (Valentim, 2008, p. 161)

A gestão do conhecimento caracteriza-se pelo conjunto de práticas de captura, armazenamento, recuperação e distribuição de ativos tangíveis de conhecimento. Essas práticas pressupõem a adoção de uma diversidade de fontes, a utilização de bancos de dados internos e externos e de medidas que incentivem o compartilhamento de conhecimentos. Além disso, a gestão do conhecimento busca coletar, organizar e disseminar conhecimentos intangíveis, como a criatividade, a especialização profissional, as experiências individuais, entre outros. Tudo isso para criar um ambiente de aprendizado interativo, de modo que a transferência do conhecimento seja um processo constante, auxiliando na criação de novos conhecimentos.

Para fazer a efetiva Gestão do Conhecimento, há que observar as dimensões do conhecimento, com base na cultura e no clima da organização, na estrutura de suas atividades e processos e na 
transformação dos dados em informações através da interação entre os sistemas e eventos, conforme o Quadro 2, a seguir.

\begin{tabular}{|l|l|}
\hline $\begin{array}{l}\text { Como } \\
\text { filosofia }\end{array}$ & $\begin{array}{l}\text { Nesta dimensão, está ligada ao clima organizacional e à própria cultura da } \\
\text { organização, seus valores, ética e moral e a uma visão que enfatiza o } \\
\text { conhecimento, seu uso, troca, criação de valor e inovação, a partir da } \\
\text { comunicação ampla e do comprometimento das lideranças para que haja } \\
\text { um extenso e contínuo diálogo, além de um ambiente propício para o } \\
\text { compartilhamento do conhecimento. }\end{array}$ \\
\hline $\begin{array}{l}\text { Como } \\
\text { processo }\end{array}$ & $\begin{array}{l}\text { Está ligada estruturalmente às atividades e tarefas necessárias à coleta, } \\
\text { acumulação, organização, controle, disponibilização e uso do conhecimento } \\
\text { por parte de todos os colaboradores da organização. Neste cenário, a } \\
\text { ênfase se dá aos processos ligados à implementação de sistemas e à } \\
\text { infraestrutura informacional e de conhecimento, à coleta de dados, ao } \\
\text { resgate de informações e conhecimentos, à construção de repositórios de } \\
\text { conhecimento (rede de especialistas, cadastro de fontes de informação), à } \\
\text { arquitetura de informação (bancos de dados, redes de comunicação, } \\
\text { intranets), necessários à real implementação de sistemas de gestão do } \\
\text { conhecimento. }\end{array}$ \\
\hline Como objeto & $\begin{array}{l}\text { Nesta dimensão, refere-se aos eventos, aos dados que, por atribuição de } \\
\text { significados, se transformam em informaçães, que, por sua vez, se } \\
\text { transformam em conhecimento a partir de processos interpretativos e } \\
\text { reflexivos. o conhecimento por seu lado pode ser subdividido em outros } \\
\text { subsistemas: os conhecimentos científicos, os técnicos e procedimentais e } \\
\text { os administrativos. }\end{array}$ \\
\hline
\end{tabular}

\section{Quadro 2: As dimensões do conhecimento}

Fonte: adaptado de Dudziak et al. (2002)

Quando se pensa em gerir o conhecimento para produzir resultados que sirvam para a tomada de decisões, é preciso definir que tipo de informação é relevante para a organização. Segundo Choo (2006, p. 30), durante este processo, a principal atividade é o processamento e a análise da informação a partir das alternativas possíveis, cujas vantagens e desvantagens são pesadas. A organização do conhecimento deve possuir informações que possam basear suas ações, a fim de conferirem-lhe vantagens ante a concorrência. No caso, pode-se entender o ato de "produzir resultados" como um processo ligado à produção e gestão documental, atividades que serão descritas a seguir. 


\subsection{GESTÃO DOCUMENTAL}

Segundo Paes (2005, p. 16), arquivo é a acumulação ordenada dos documentos, em sua maioria textuais, criados por uma instituição ou pessoa no curso de sua atividade, e preservados para a consecução de seus objetivos, visando à utilidade que poderão oferecer no futuro. A função básica de um arquivo é disponibilizar as informações contidas no acervo sob sua guarda.

Schellenberg (2006, p. 41) define arquivos: "Os documentos de qualquer instituição pública ou privada que hajam sido considerados de valor, merecendo preservação permanente para fins de referência e de pesquisa e que hajam sido depositados ou selecionados para depósito, num arquivo de custódia permanente".

De acordo com a Lei Federal n. 8.159 (1991), "considera-se gestão de documentos o conjunto de procedimentos e operações técnicas referentes a sua produção, tramitação, uso, avaliação e arquivamento em fase corrente e intermediária, visando a sua eliminação ou recolhimento para guarda permanente".

Os documentos de arquivo são os suportes onde estão registradas as informações necessárias para o funcionamento da organização, e o que difere esses documentos quanto a sua importância são sua natureza, objetivos e usos.

Se os arquivos são conjuntos orgânicos de informações registradas em suportes tradicionais ou eletrônicos, cujos conteúdos são relativos à criação, ao funcionamento, à evolução, às atividades, às transações, às transformações estruturais e funcionais, assim como às relações internas e externas de uma entidade pública ou privada, podendo ser ainda os conjuntos das informações relativas à vida civil e profissional das pessoas físicas, eles (os arquivos) podem ser considerados como recursos probatórios e informativos. A "informação arquivística" faz parte dos recursos documentais que, ao lado dos recursos humanos, financeiros e materiais, toda organização utiliza para seu funcionamento. (Bellotto, 2014, p. 298)

Com relação às atividades de gestão documental, destacam-se a produção, o uso e a destinação de documentos, como seguem:

- produção: refere-se à elaboração dos documentos, de acordo com as atividades de uma organização ou área específica. De acordo com Paes (2005, p. 54), durante esta fase, é papel do profissional arquivista 
contribuir para que sejam criados apenas documentos essenciais à administração da instituição, evitando a emissão de vias desnecessárias, visando à compreensão e interpretação dos textos. Além disso, deve contribuir na apresentação de estudos sobre a adequação e o melhor aproveitamento de recursos nesta produção;

- uso: compreende as atividades de protocolo, expedição, organização e arquivamento de documentos em fase corrente e intermediária, bem como a elaboração de normas de acesso aos documentos e a recuperação de informações para uso administrativo;

- avaliação e destinação: atividade de análise para estabelecimento dos prazos de guarda dos documentos, determinando quais serão encaminhados para arquivamento permanente e quais deverão ser eliminados por terem perdido seu valor de prova e informação relevante.

A avaliação ou análise documental é uma atividade crítica no processo de gestão de documentos e possibilita o questionamento e verificação da real necessidade de guarda de um documento, na medida em que obriga o avaliador a observar o valor informativo e implicações jurídica, fiscal, técnica, administrativa e histórica dos documentos, e com base nestes fatores, estabelece o prazo de guarda dos documentos e sua destinação, dando origem à tabela de temporalidade. (Souto, 2014, p. 275)

A avaliação documental é um processo que tem caráter multidisciplinar, no qual uma comissão formada por profissionais de diversas áreas da organização deliberam a respeito dos valores de cada documento e definem sua destinação. Essa deliberação está diretamente envolvida com a troca de experiências e transmissão de conhecimento a respeito da importância da informação contida nos documentos produzidos pela instituição. Segundo Souto (2014, p. 275), a avaliação ou análise documental é uma atividade crítica no processo de gestão de documentos e possibilita o questionamento e a verificação da real necessidade de guarda de um documento, na medida em que obriga o avaliador a observar o valor informativo e suas implicações.

Essas atividades geram a elaboração do plano de classificação e da tabela de temporalidade de documentos de arquivo, instrumentos essenciais para garantir a organização e a consolidação dos resultados da avaliação, garantindo a eliminação de documentos cuja guarda não é mais 
necessária, bem como a preservação dos documentos de valor histórico ou informativo.

Segundo Bernardes e Delatorre (2008, p. 36), a tabela de temporalidade de documentos de arquivo é o instrumento de gestão, resultante da avaliação documental, aprovado por autoridade competente, que define prazos de guarda e a destinação de cada série documental, determinando sua preservação ou autorizando sua eliminação. Por se tratar de um instrumento dinâmico, é essencial que a tabela de temporalidade seja periodicamente atualizada, sempre considerando as atividades de avaliação documental anteriormente descritas.

Observando as atividades inerentes à área de gestão de documentos, e com base nos conceitos apresentados, podemos encontrar interfaces entre as atribuições do profissional arquivista e as práticas de gestão do conhecimento, conforme será explicitado no próximo capítulo.

\section{RESULTADOS: A INTERFACE ENTRE GESTÃO DOCUMENTAL, GESTÃO DA INFORMAÇÃO E GESTÃO DO CONHECIMENTO}

Conforme apontado anteriormente neste trabalho, é de suma importância a organização de informações, pois elas são a base para a tomada de decisões de uma organização e, para tanto, é fundamental o trabalho do profissional da informação, aqui representado pelo profissional da área de arquivos. No contexto do mundo globalizado, faz-se necessária a redefinição das atividades inerentes à gestão da informação, uma vez que o profissional da área precisa conhecer todos os setores envolvidos na produção, uso e disseminação dos documentos que contêm informações relevantes para a continuidade dos negócios.

O profissional da informação eficaz é aquele que usa uma abordagem sistemática para analisar e solucionar problemas, constrói uma infraestrutura orgânica baseada em estratégias sólidas, entende as necessidades singulares dos clientes e resolve falhas de comunicação. 0 profissional da informação precisa exercer sua liderança para resolver crises e/ou capitalizar oportunidades, aplicando metodologias coerentes e estruturadas no desenvolvimento dos sistemas de informação. Precisa conhecer não apenas uma área ou setor, mas toda a organização para a qual trabalha, podendo assim fazer frente às mudanças e aos desafios diários. Este profissional tem um senso de propósito fortemente delineado, tem humildade para continuar aprendendo, estando sempre disposto a 
reinventar a si mesmo, com a mente aberta às novas ideias e experiências. Precisa incorporar a perspectiva de um psicólogo, a criatividade de um arquiteto e a agilidade de um atleta. Essas características, essenciais ao mercado competitivo dos dias de hoje, são parte do elenco de habilidades e competências que devem ser conferidas aos novos profissionais da informação pelas universidades e instituições acadêmicas, dentro de programas específicos, com currículos básicos adequados à realidade dos tempos modernos (Souto, 2014, p. 166).

Observando a citação acima, e identificando o profissional da área de arquivos como um profissional da informação, é possível entender a proximidade entre essas demandas e as competências dos trabalhadores do conhecimento, uma vez que existe a semelhança entre as práticas de gestão documental e as de gestão do conhecimento. Luz (2010, p. 36) corrobora esse pensamento com esta afirmação:

Não existe uma fórmula, mas para o arquivista, aqui então caracterizado como um profissional da informação, surge a possibilidade de integrar e comandar equipes em todas as fases do processo de implantação do programa de gestão do conhecimento, seja antes disso, quando da necessidade de estabelecer a gestão documental, seja na fase de planejamento e levantamento de informações, seja no processo de implementação e até na divulgação e estímulo ao uso da gestão do conhecimento nas corporações.

No Quadro 3, a seguir, analisam-se as similaridades e as diferenças entre as áreas, com base no estudo feito por Santos (2013).

\begin{tabular}{|c|c|c|c|}
\hline & $\begin{array}{l}\text { Gestão dos } \\
\text { documentos }\end{array}$ & $\begin{array}{l}\text { Gestão da } \\
\text { informação }\end{array}$ & $\begin{array}{l}\text { Gestão do } \\
\text { conhecimento }\end{array}$ \\
\hline Foco & \begin{tabular}{l}
\multicolumn{2}{c}{ Fundo } \\
arquivístico, acervo \\
orgânico
\end{tabular} & $\begin{array}{l}\text { Calcado sobre a } \\
\text { informação em geral }\end{array}$ & pessoas Tem como foco as \\
\hline Objetivo & $\begin{array}{ll}\text { Assegurar a } \\
\text { autenticidade } \\
\text { dos } \\
\text { documentos } \\
\text { orgânicos; } \\
\text { Comprovar } \\
\text { fidelidade dos } \\
\text { processos; } \\
\text { Eficiência e } \\
\text { eficácia } \\
\text { administrativa. } \\
\end{array}$ & $\begin{array}{l}\text { Dar suporte aos } \\
\text { processos } \\
\text { internos; } \\
\text { - Assegurar a } \\
\text { qualidade das } \\
\text { operações; } \\
\text { Eficiência e } \\
\text { eficácia } \\
\text { administrativa. } \\
\end{array}$ & $\begin{array}{ll}\text { - } & \text { Facilitar as relações; } \\
\text { - } & \text { desegurar } \\
& \text { inovaçãvimento contínuos; } \\
\text { - Eficiência e eficácia } & \text { administrativa. }\end{array}$ \\
\hline $\begin{array}{l}\text { Objeto de } \\
\text { estudo }\end{array}$ & $\begin{array}{|lr|} & \text { Documentos } \\
\text { ou } & \text { informação } \\
\text { orgânicos como objeto }\end{array}$ & $\begin{array}{l}\text { Informação } \\
\text { como objeto }\end{array}$ & $\begin{array}{l}\text { Conhecimento como } \\
\text { conceito. }\end{array}$ \\
\hline $\begin{array}{l}\text { Instrumentos } \\
\text { (exemplos) }\end{array}$ & $\begin{array}{l}\text { Plano de } \\
\text { classificação; Tabela de } \\
\text { temporalidade; Manual } \\
\text { de redação }\end{array}$ & $\begin{array}{ll}\text { - } & \text { Taxonomias } \\
\text { - } & \text { Tesauros } \\
\text { - Índices, etc. }\end{array}$ & $\begin{array}{ll}\text { - } & \text { Mapas de } \\
& \text { conhecimento } \\
\text { - } & \text { Banco de } \\
& \text { competências } \\
\text { - } & \text { Intranet, etc. } \\
\end{array}$ \\
\hline
\end{tabular}




\begin{tabular}{|c|c|c|c|}
\hline $\begin{array}{l}\text { Característica } \\
\text { do objeto }\end{array}$ & $\begin{array}{l}\text { Documentos e } \\
\text { informação arquivística } \\
\text { são explícitos e factuais }\end{array}$ & $\begin{array}{l}\text { Informação é } \\
\text { explícita e factual. }\end{array}$ & $\begin{array}{l}\text { Conhecimento } \\
\text { tácito, mas também explícito. }\end{array}$ \\
\hline $\begin{array}{l}\text { Áreas de } \\
\text { concentração } \\
\text { e interesses } \\
\text { (exemplos) }\end{array}$ & 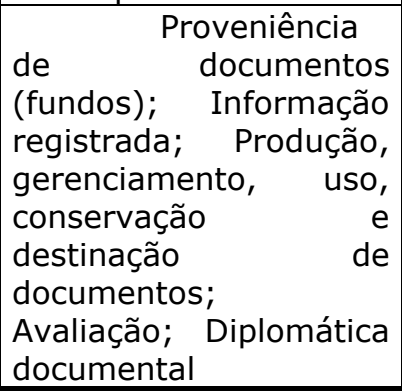 & $\begin{array}{ll}\text { - } & \text { Comunicação } \\
& \text { humana; } \\
\text { - } & \text { Efetividade, } \\
& \text { eficácia e } \\
& \text { relevância; } \\
\text { - Informação: uso, } & \text { necessidades; } \\
\text { - Tecnologia da } \\
\text { informação. } \\
\end{array}$ & $\begin{array}{ll}\text { - } & \text { Mapeamento e } \\
& \text { registro do } \\
\text { conhecimento; } \\
\text { - Compartilhamento e } \\
\text { transferência do } \\
\text { conhecimento; } \\
\text { Uso e reúso do } \\
\text { conhecimento; } \\
\text { - Gerenciamento de } \\
\text { competências. }\end{array}$ \\
\hline
\end{tabular}

\section{Quadro 3: Relações entre gestão documental, gestão da informação e gestão do conhecimento}

Fonte: adaptado de Santos (2013, p. 195)

De acordo com o exposto no Quadro 3, é possível, por meio de análise comparativa das práticas arquivísticas e das atividades de gestão da informação e do conhecimento, encontrar as formas em que a gestão documental atua como auxiliar nos processos. Por exemplo, o plano de classificação, na medida em que é produzido por meio de análise profunda das atividades-meio ou fim de uma organização, acaba contribuindo para a criação de mapas de conhecimento, uma vez que os setores e atividades da instituição são administrados e executados por funcionários e colaboradores que possuem conhecimento e habilidades passíveis de serem identificados e registrados.

Da mesma forma, a nomeação de uma comissão de avaliação de documentos pode resultar no estabelecimento de uma ou mais comunidades de prática, já que a análise documental também passa pela identificação dos processos internos, sendo capaz de apontar caminhos para a inovação. Sendo assim, há oportunidade para grupos trabalharem paralelamente em torno de uma cultura de inovação, propondo opções para melhoria de atividades e até no próprio desenvolvimento e gestão de documentos, formando assim um ciclo virtuoso de atividades. Comissões de Avaliação de Documentos são grupos multidisciplinares, mais uma semelhança com comunidades de prática. Ainda que a segunda tenha como característica a formação autorregulada e o funcionamento espontâneo, carece de governança, e pode aproveitar-se da formalidade das comissões como alicerce para sua manutenção. 
Dentro da área de concentração da gestão do conhecimento, é clara a intenção do uso e reúso deste conhecimento. Neste ponto, a gestão documental entra como inegável recurso de registro dos fluxos formais do conhecimento, na figura dos documentos. Cabe então ao profissional da informação a competência para gerir e, por meio da regulamentação específica da área de arquivos, controlar o acesso, a utilização e a disseminação desse conhecimento registrado.

Retomando os conceitos apresentados por Davenport e Prusak (1998, p. 6), o conhecimento deriva da informação que é entregue, além dos contatos interpessoais, através de meios estruturados, como livros e documentos. Nesse sentido, ainda que o conhecimento esteja mais próximo da ação e da tomada de decisões, há que se verificar a importância dos registros e dos instrumentos da gestão documental como auxiliares dessas ações, uma vez que estes podem funcionar como auxiliares no mapeamento e uso do conhecimento organizacional. Em documentos e registros eletrônicos, a taxonomia simplifica a busca, avaliação e destinação das informações, o que mostra a interligação entre os modelos de gestão. Segundo Santos (2013, p. 196), é possível observar que os planos de classificação, taxonomias e mapas de conhecimento têm estruturas hierárquicas similares.

A seguir, na Figura 2, apresentam-se graficamente algumas possibilidades para que a Gestão Documental seja interpretada como auxiliar nos processos de Gestão da Informação e do Conhecimento.

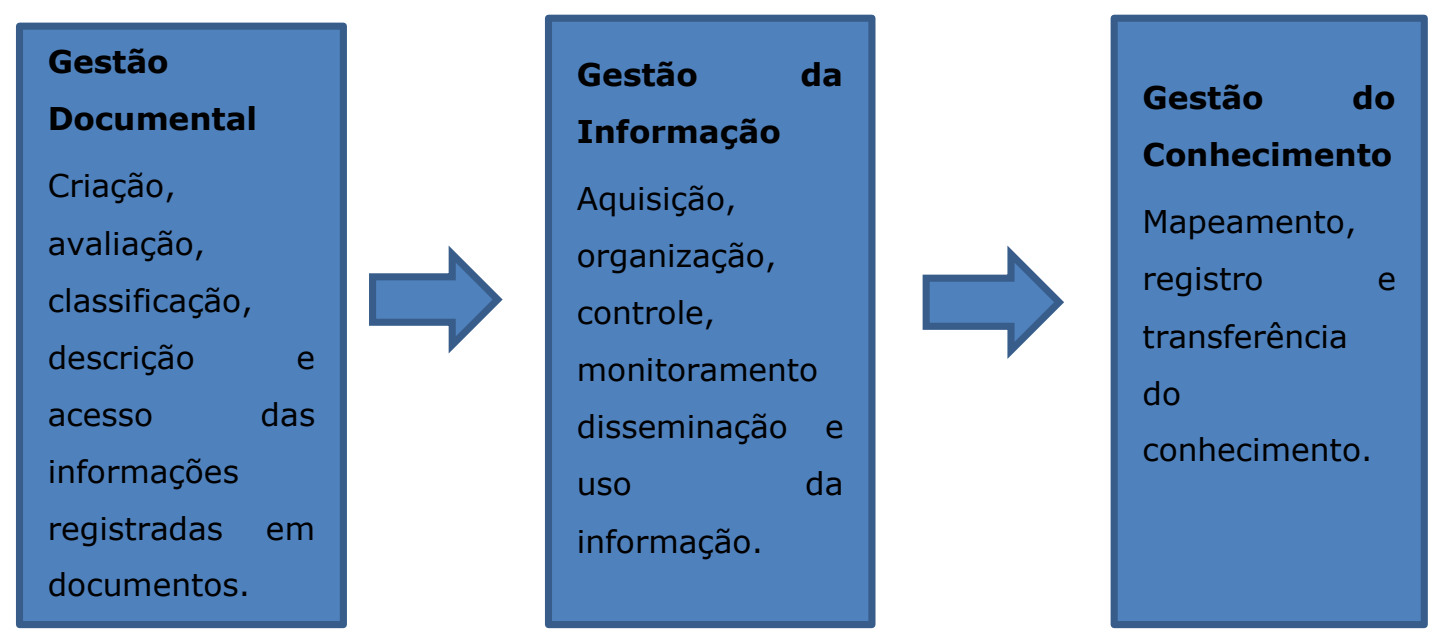

Figura 2: Interfaces entre gestão documental, gestão da informação e gestão do conhecimento 
De acordo com a Figura 3, denota-se que a gestão documental tem como papel fundamental regulamentar e gerir os registros em seus variados suportes, de modo que a gestão da informação seja capaz de disseminá-la e servir como apoio para a gestão do conhecimento, auxiliando na identificação e no mapeamento do conhecimento, deixando-o disponível para uso e desenvolvimento dos indivíduos da organização.

Ainda apontando as similaridades entre as atividades de gestão documental e as práticas de gestão do conhecimento, a avaliação de documentos que leva à definição da destinação final, encontra muitas semelhanças com os processos de lições aprendidas, uma vez que a revisão de prazos de guarda tem de levar em conta as ocorrências com as informações contidas nos documentos, a frequência de acessos e a possibilidade de recuperação da informação. Esta e outras atividades devem estar registradas em um procedimento interno, de modo a facilitar a comunicação interna e explicitar as políticas que norteiam a gestão dos documentos da organização.

\section{RECOMENDAÇÕES E CONSIDERAÇÕES FINAIS}

Há certo equívoco por parte de algumas instituições, ao tratar as áreas de arquivo e as próprias atividades de gestão documental como áreas e processos menores da organização. Até pela característica ainda presente em boa parte dos arquivos e centros de documentação, de concentrarem grandes quantidades de massa documental acumulada, decorrente da falta de recursos causada pela visão relatada no início do parágrafo, há dificuldade em representar a gestão documental como atividade fundamental nos processos das instituições.

Ainda que haja o estabelecimento de normas específicas para a gestão de documentos, falta às organizações a visão de longo prazo no sentido de utilizar a memória corporativa como alicerce para as ações e tomadas de decisão. Os arquivos ainda são vistos no caráter consultivo, para auxiliar como prova quando há demanda judicial ou administrativa, mas ainda não são considerados como uma possibilidade de instrumento de aprendizado, na medida em que são o registro de atividades passadas, que 
tenham ou não resultado em sucesso nas operações administrativas ou comerciais.

Este trabalho, em sua essência e viés acadêmicos, buscou, por meio da pesquisa bibliográfica e da análise comparativa, identificar possibilidades de integração entre disciplinas e práticas, a fim de que o profissional de arquivos se insira na gestão do conhecimento, uma vez que é guardião de informações importantes no estabelecimento de processos que levam à criação de novos conhecimentos, que levam à inovação. Acredita-se que foi possível, por meio desta revisão literária, mostrar que há espaço para que as práticas arquivísticas sirvam como alicerce às ações de gestão do conhecimento, uma vez que, através da clareza de informações organizadas devidamente, é possível criar novos conhecimentos, por meio da integração com os demais processos. Entretanto, constatou-se que ainda há pouca produção textual referenciando essa integração, restrita a algumas das publicações e artigos utilizados nesta pesquisa. Isso denota que ainda há um campo amplo para explorar nesse sentido. A gestão documental é determinante, sobretudo pelo fato de haver normas e procedimentos estabelecidos que assegurem a eficiência nas ações. Há, segundo Santos (2013, p. 219), a ideia de que práticas de gestão de documentos e de informação não garantem aplicação de gestão do conhecimento, porém esta não é possível sem as práticas de gestão de documentos e da informação. 0 intuito então foi buscar maior aproximação dos conceitos, para que a integração fosse facilitada.

Por outro lado, e em caráter não explorado neste trabalho, e que se propõe para futura pesquisa, as práticas de gestão do conhecimento e da inovação, assim como se valem da gestão documental para efetivar seu funcionamento, podem ser úteis para modernizar e renovar a gestão documental. Comunidades de prática, mapas de conhecimento, atividades de criação coletiva, entre outros, se aplicados à prática arquivística, podem ajudar a área de arquivos a ser vista de forma diferente pela organização, se os procedimentos forem adotados com critério e dedicação, de modo a produzir resultados efetivos.

Por fim, conclui-se que a gestão do conhecimento é um processo contínuo e que a memória corporativa, por meio de uma eficiente gestão 
documental, mostra-se fundamental no processo, uma vez que somente olhando para o passado, analisando os erros e acertos, as organizações podem preparar-se adequadamente para os desafios do futuro. Aos profissionais da informação, cabe enxergar esse papel de apoiadores dos processos, para que juntos possam garantir a sustentabilidade dos negócios, através do crescimento contínuo e próspero.

\section{REFERÊNCIAS}

Bellotto, H. L. (2014). Arquivo: estudos e reflexões. Belo Horizonte: Editora UFMG.

Bernardes, I. P., \& Delatorre, H. (2008). Gestão documental aplicada. São Paulo: Arquivo Público do Estado de São Paulo. Recuperado em 5 de novembro, 2014, de http://www.arquivoestado.sp.gov.br/site/assets/publicacao/anexo/gesta o_documental_aplicada.pdf

Chauí, M. (2000). Convite à filosofia. São Paulo: Ática.

Choo, C. W. (2006). A organização do conhecimento: como as organizações usam a informação para criar significado, construir conhecimento e tomar decisões. São Paulo: Senac São Paulo.

Davenport, T. H., \& Prusak, L. (1998). Conhecimento empresarial: como as organizações gerenciam o seu capital intelectual (4a ed.). Rio de Janeiro: Campus.

Dudziak, A. E. et al. (2002). Gestão do conhecimento em bibliotecas universitárias. Anais do Seminário Nacional de Bibliotecas Universitárias, 12, Recife, PE, Brasil. Recuperado em 11 de outubro, 2014, de http://www.sibi.ufrj.br/snbu/snbu2002/oralpdf/91.a.pdf

Lastres, \& Ferraz (1999)

Lei n. 8.159, de 08 de janeiro de 1991. Dispõe sobre a política nacional de arquivos públicos e privados e dá outras providências. Diário Oficial da União, Brasília, 09 de janeiro de 1991. Poder Executivo.

Lemos (1999)

Longo, R. M. J. et al. (2014). Gestão do conhecimento: a mudança de paradigmas empresariais no século XXI. São Paulo: Senac São Paulo.

Luz, C. (2010). Arquivologia 2.0: a informação digital humana. Excertos de um arquivista 2.0 no mundo digital. Florianópolis: Bookess.

Moreira (2010) 
Morin, E. (2000). Os sete saberes necessários à educação do futuro. Recuperado em 13 de agosto, 2014, de http://tudosobre.com/concursos/3/MORIN,\%20Edgar\%200s\%20Sete\%2 OSaberes.pdf

Paes, M. L. (2005). Arquivo: teoria e prática (3a ed.) Rio de Janeiro: Editora FGV.

Santos, V. B. dos (Org.); Innarelli, H. C., \& Sousa, R. T. B. de. (2013). Arquivística: temas contemporâneos (3a ed.). Brasília, DF: Senac.

Schellenberg, T. R. (2006). Arquivos modernos: princípios e técnicas (6a ed.). Rio de Janeiro: Editora FGV.

Senge, P. M. (2011). A quinta disciplina: arte e prática da organização que aprende (27a ed.). Rio de Janeiro: Best Seller.

Souto, L. F. (Org.). (2014). Gestão da informação e do conhecimento: práticas e reflexões. Rio de Janeiro: Interciência.

Starec, C. (Org.). (2012). Gestão da informação, inovação e inteligência competitiva: como transformar a informação em vantagem competitiva nas organizações. São Paulo: Saraiva.

Takeuchi, H., \& Nonaka, I. (2008). Gestão do conhecimento. Porto Alegre: Bookman.

Teixeira Filho, J. (2010). Estratégias para o caos: sobre a transposição de teorias da física e da matemática para a administração. Recuperado em 13 de agosto, 2014, de http://www.senac.br/BTS/251/boltec251c.htm

Turra, N. C. (2007, julho-dezembro). Reuven Feuerstein: "Experiência de aprendizagem mediada: um salto para a modificabilidade cognitiva estrutura". Educere et Educare, 2(4), 297-310. Recuperado em 13 de agosto, 2014, de http://erevista.unioeste.br/index.php/educereeteducare/article/download $/ 1671 / 1358$

Valentim, M. L. P. (Org.). (2008). Gestão da informação e do conhecimento no âmbito da ciência da informação. São Paulo: Polis; Cultura Acadêmica. 